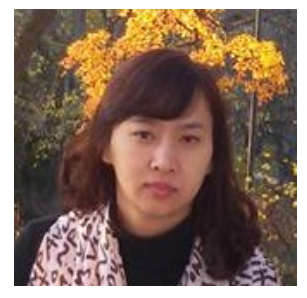

\title{
Using Quizlet to Engage the Students in Learning Vocabulary
}

Linh Pham

Thainguyen Gifted High School, Dong Thap Province

\begin{abstract}
For most of the students, learning vocabulary is rather monotonous, and it is rather difficult to remember
\end{abstract} all of the new words. To make the lessons more appealing to them, the presenter will discuss how to adapt Quizlet to teaching vocabulary effectively to involve the students in learning vocabulary.

\section{Session Description}

EFL students "know that vocabulary is [crucial] in understanding texts, and long-term...retention is difficult" (Bauer-Ramazani, 2015). However, they find it boring and wearisome to learn words by heart, and sometimes the students even feel tired of trying to remember the vocabulary. Also, the EFL teachers have many challenges in encouraging and engaging their students in the vocabulary lessons. To reduce the burden on the teachers' shoulders, this presentation reports on the effectiveness of Quizlet for teaching and learning vocabulary. "Quizlet is a free Web 2.0 [tool] and mobile app vocabulary flashcard and study program...Unlike the traditional [word] lists and other flashcard programs, Quizlet offers students multiple ways to interact with each word” (Bauer-Ramazani, 2015). This presentation discusses how to make flashcards to match definitions with their respective words and how to guide the students to listen to model pronunciations of those words. For example, with the phrase "football player," the students will have the definition, the picture of a football player and they can hear how this phrase is pronounced. Students can also see how to spell the words they hear, how to check their progress, how to use games for reviewing, and how to find practice tests to take. These intentional vocabulary learning activities expose learners to multiple interactions with the vocabulary necessary for retention (Folse, 2004, Nation, 1990, 2011; Schmitt, 2000 as cited in Bauer-Ramazani, 2015). These activities also support expanded rehearsal (Nakata, 2011 as cited in Bauer-Ramazani, 2015). With the help of Quizlet, the EFL teachers will find it easier 
to engage and involve their students into learning vocabulary and the students will be more engaged in learning and will study more actively and more effectively.

\section{References}

Bauer-Ramazani, C. (2015). Action research: Using Quizlet for mobile vocabulary learning and retention.

Retrieved from: http://tesolpresent.pbworks.com/w/page/90006548/Action-Research-Quizlet.

Folse, K. (2004). Myths about teaching and learning second language vocabulary: What recent research says. TESL Reporter, 37(2), 1-13.

Nakata, T. (2011). Computer-assisted second language vocabulary learning in a paired-associate paradigm: a critical investigation of flashcard software. Computer Assisted Language Learning, 24(1), 17-38.

Nation, I. S. P. (1990). Teaching and learning vocabulary. New York: Newbury House.

Nation, I. S. P. (2011). Research into practice: Vocabulary. Language Teaching, 44 (4), 529-539.

Schmitt, N. (2000). Vocabulary in language teaching. Cambridge, U.K: Cambridge University Press. 